\title{
Ionospheric storms at geophysically-equivalent sites - Part 1: Storm-time patterns for sub-auroral ionospheres
}

\author{
M. Mendillo and C. Narvaez \\ Center for Space Physics, Boston University, Boston, MA 02215, USA \\ Received: 23 December 2008 - Revised: 3 March 2009 - Accepted: 24 March 2009 - Published: 7 April 2009
}

\begin{abstract}
The systematic study of ionospheric storms has been conducted primarily with groundbased data from the Northern Hemisphere. Significant progress has been made in defining typical morphology patterns at all latitudes; mechanisms have been identified and tested via modeling. At higher mid-latitudes (sites that are typically sub-auroral during non-storm conditions), the processes that change significantly during storms can be of comparable magnitudes, but with different time constants. These include ionospheric plasma dynamics from the penetration of magnetospheric electric fields, enhancements to thermospheric winds due to auroral and Joule heating inputs, disturbance dynamo electrodynamics driven by such winds, and thermospheric composition changes due to the changed circulation patterns. The $\sim 12^{\circ}$ tilt of the geomagnetic field axis causes significant longitude effects in all of these processes in the Northern Hemisphere. A complementary series of longitude effects would be expected to occur in the Southern Hemisphere. In this paper we begin a series of studies to investigate the longitudinal-hemispheric similarities and differences in the response of the ionosphere's peak electron density to geomagnetic storms.

The ionosonde stations at Wallops Island (VA) and Hobart (Tasmania) have comparable geographic and geomagnetic latitudes for sub-auroral locations, are situated at longitudes close to that of the dipole tilt, and thus serve as our candidate station-pair choice for studies of ionospheric storms at geophysically-comparable locations. They have an excellent record of observations of the ionospheric penetration frequency $(f o \mathrm{~F} 2)$ spanning several solar cycles, and thus are suitable for long-term studies. During solar cycle \#20 (1964-1976), 206 geomagnetic storms occurred that had $A_{p} \geq 30$ or $K_{p} \geq 5$ for at least one day of the storm. Our anal-
\end{abstract}

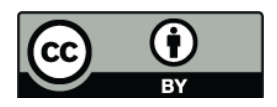

Correspondence to: C. Narvaez (cnarvaez@bu.edu) ysis of average storm-time perturbations (percent deviations from the monthly means) showed a remarkable agreement at both sites under a variety of conditions. Yet, small differences do appear, and in systematic ways. We attempt to relate these to stresses imposed over a few days of a storm that mimic longer term morphology patterns occurring over seasonal and solar cycle time spans. Storm effects versus season point to possible mechanisms having hemispheric differences (as opposed to simply seasonal differences) in how solar wind energy is transmitted through the magnetosphere into the thermosphere-ionosphere system. Storm effects versus the strength of a geomagnetic storm may, similarly, be related to patterns seen during years of maximum versus minimum solar activity.

Keywords. Ionosphere (Ionospheric disturbances; Midlatitude ionosphere; General or miscellaneous)

\section{Introduction}

The response of the ionosphere to increases in geomagnetic activity has been a central topic of study since the earliest days of solar-terrestrial space science. Many important reviews of this field have been written (e.g., Obayashi, 1964; Matuura, 1972; Prölss, 1995), with a recent comparison and assessment of them in Mendillo (2006). From a broad perspective, the morphology patterns of ionospheric storms at middle and low latitudes are rather well known, and the dominant mechanisms responsible for them have been identified and modeled. A significant number of case studies have been published, many dealing with strong storms that show the extremes capable of being achieved by specific mechanisms. An important message to come from all of these past studies is that there are no new physical mechanisms that appear within the F-layer only during storms, or that unique scalings or saturation phenomena occur only during storms.

Published by Copernicus Publications on behalf of the European Geosciences Union. 
The same processes that govern the ambient ionosphere, as embodied in the classic electron density continuity equation (Rishbeth and Garriott, 1969; Schunk and Nagy, 2009) photo-production, chemical loss, and transport by thermal expansion, neutral winds, waves, tides and electric fields of internal and external origin - all act during periods of disturbance. The modified magnitudes, phases and time-constants of those processes blend is different ways during each storm, and thus the challenge facing current research is to characterize such effects correctly and to implement them into current models.

Ionospheric storm effects vary with latitude, and thus opportunities to study the blending of processes are themselves functions of latitude. For example, horizontal convection dominates in the polar caps, and auroral particle precipitation and electrodynamics in the auroral zones, while expansions and contractions of the equatorial ionization anomaly (EIA) drive the strongest effects at low latitudes. A sub-auroral site provides a good example of a location where multiple mechanisms can have comparable effects and thus the study of blending and the coupling of processes from higher and lower latitudes might be particularly fruitful at such locations.

Defining precisely what constitutes a sub-auroral site is fraught with difficulties, so here we offer a broad set of attributes: (1) under quiet conditions, the $L=2-3$ domain is always within the plasmasphere during the daytime hours, but might include plasmapause/ionospheric trough locations during portions of the night near $L=3\left(\sim 55^{\circ}\right.$ magnetic latitude). During storms, (2) a sub-auroral site often remains within the plasmasphere during daytime hours, but it is usually poleward of the plasmapause after sunset. Thus, dramatic ionospheric signatures of dynamical plasmaspheric processes occur from local noon to dusk, contributing to daytime positive phase ionospheric storms (Lanzerotti et al., 1975), followed by sharp transitions to being beyond the plasmapause after sunset (Mendillo et al., 1974). The plasmaspheric influence continues after sunset when flux tubes are held in convective "stagnation" while chemical loss proceeds for many hours prior to sunrise. Thus, the onset of the negative phase is due both to dynamics and chemistry. Consistent with this behavior is the pronounced intrusion of trough/plasmapause/ring current effects that lead to the appearance of stable auroral red (SAR) arcs (Foster et al., 1994; Baumgardner et al., 2008). Condition (3) deals with storm-time auroral heating of the thermosphere by precipitating particles and currents (Joule heating), processes that generally occurs poleward of $L \sim 2.5$ (except during the most severe storms). Two effects at sub-auroral latitudes result from auroral heating - increases in equatorward meridional winds that can contribute to positive-phase ionospheric storms, and composition changes (specifically, decreases in the $\mathrm{O} / \mathrm{N}_{2}$ ratio) due to disturbed circulation patterns that lead to the long duration negative phase of ionospheric storms (Prölss, 1995). Finally, (4) due to the $\sim 12^{\circ}$ tilt of the geomagnetic field axis, all of the above processes show an important longitude pattern. In the Northern Hemisphere, the dipole tilt results in geographic midlatitudes $(\sim 45 \mathrm{~N})$ having the highest magnetic latitudes $(\sim 57 \mathrm{~N})$ in the $\sim 70 \mathrm{~W}$ longitude sector. This means that, in this unique sector for the Northern Hemisphere, solar ionization (ordered by solar zenith angle and therefore the same at a given latitude for all longitudes) produces the most robust F-layer capable of being influenced by magnetospheric processes (ordered by geomagnetic latitude). The opposite is true for the ionosphere in the Northern Hemisphere near longitudes of $\sim 110 \mathrm{E}$ where $45 \mathrm{~N}$ geographical corresponds to $\sim 33 \mathrm{~N}$ magnetically. Yet, the same F-layer production at $45 \mathrm{~N}$ is more susceptible to neutral wind effects there due to the more favorable geometric factor $(\sin I \cos I$, where $I$ is the geomagnetic inclination angle) for vertical motions. In the Southern Hemisphere, the same "special" longitudes play opposite roles, with $\sim 70 \mathrm{~W}$ as the sector most susceptible to effects driven by disturbance winds and $\sim 110 \mathrm{E}$ as the region most influenced by penetration electrodynamics.

The longitude-hemisphere effect upon ionospheric storms summarized above has been well known for some time. A basic approach to modeling key processes in the two hemispheres appeared in Mendillo et al. (1992). Yet, there has been little effort to date to test these concepts using long-term observations of ionospheric storms in both hemispheres. In this paper, we offer a coherent approach to such an investigation.

\section{Two sub-auroral equivalent geophysical ionospheric locations}

To conduct a study as outlined above, two appropriate observation sites to use are the ionosonde stations at Wallops Island (Virginia) and Hobart (Tasmania). Their relevant coordinates are given in Table 1. There are several reasons leading to the choice of this particular pair of stations: (1) we want to conduct a study that will eventually span several solar cycles and thus ionosonde data are the only realistic choices for such long-term analyses; (2) archives of total electron content (TEC) are also available from these longitude sectors, as demonstrated in the work of Essex et al. (1981), but they are limited to years spanning solar cycle \#20, and therefore do not meet our long-term objectives; (3) GPS data would have the advantage of coverage over extensive regions in both hemispheres, but these have two drawbacks, namely, limitation to a single solar cycle (\#23) and poor long-term calibration reliability. Central to our analysis methods, to be described below, is the formation of average patterns of disturbance variations (in percent from a control curve), and thus the inherent uncertainty is absolute values for GPS TEC (typically 4-6 TEC units) is the issue of concern. While case studies of TEC storm effects are obviously prominent in the current literature (e.g., Foster and Rideout, 2005), they focus only on positive phase effects re-named "storm 
Table 1. Coordinates for the Ionosonde Stations at Wallops Island (VA), Hobart (Tasmania), Washington (D.C.) and Christchurch (NZ). To account for secular changes in the geomagnetic field, the magnetic latitudes are the averages of years 1964 and 1976 , calculated using the Definite/International Geomagnetic Reference Field (DGRF/IGRF) model. See website http://omniweb.gsfc.nasa.gov/vitmo/cgm.html.

\begin{tabular}{lcccc}
\hline & Hobart (Tasmania) & Wallops Island (VA) & Christchurch (New Zealand) & Washington $^{\mathrm{a}}$ \\
\hline Geographic Latitude & $42.9^{\circ} \mathrm{S}$ & $37.8^{\circ} \mathrm{N}$ & $46.3^{\circ} \mathrm{S}$ & $38.7^{\circ} \mathrm{N}$ \\
Geographic Longitude & $147.3^{\circ} \mathrm{E}$ & $75.5^{\circ} \mathrm{W}$ & $172.8^{\circ} \mathrm{E}$ & $71.1^{\circ} \mathrm{N}$ \\
Geomagnetic Latitude & $-54.05^{\circ}$ & $50.47^{\circ}$ & $-50.27^{\circ}$ & $51.38^{\circ}$ \\
\hline
\end{tabular}

a Ionosonde data at Washington was discontinued in 1968, and a new series of observations was started at Wallops Island. For this study of the period 1964-1976, most of the data come from Wallops Island, and thus we use that station name for the combined data set.
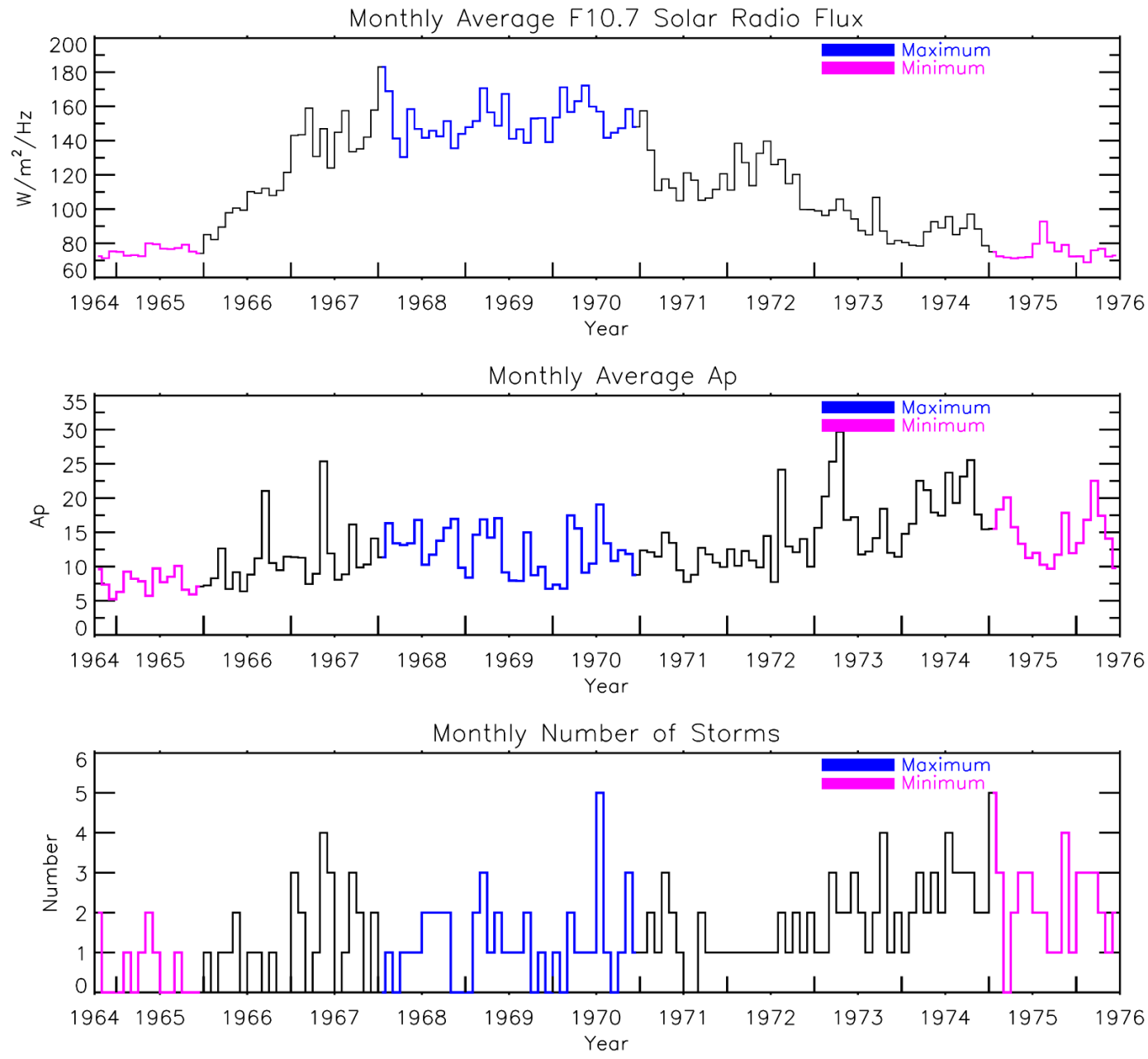

Fig. 1. Characteristics of solar cycle \#20 as portrayed by (a) the solar index F10.7 and (b) the geomagnetic index $A_{p}$. Panel (c) gives the number of storms satisfying the criteria for this study (see text), totaling 206 events. In each panel, coding is used to identify four portions of the solar cycle: Minimum, Rising, Maximum and Falling.

enhanced densities" (SEDs), morphology patterns that do not depend on precise knowledge of absolute values. This is not the case for negative storm TEC patterns when absolute calibration uncertainties have a profound effect upon percent changes, and particularly so at night when ionospheric trough values can be smaller than 4-6 TEC units in the sub-auroral domain; (4) finally, a significant number of past studies have been conducted at sub-auroral locations along the $\sim 70 \mathrm{~W}$ meridian (Matsushita, 1959; Mendillo et al., 1972; Mendillo and Klobuchar, 2006) and thus validation with previous work 

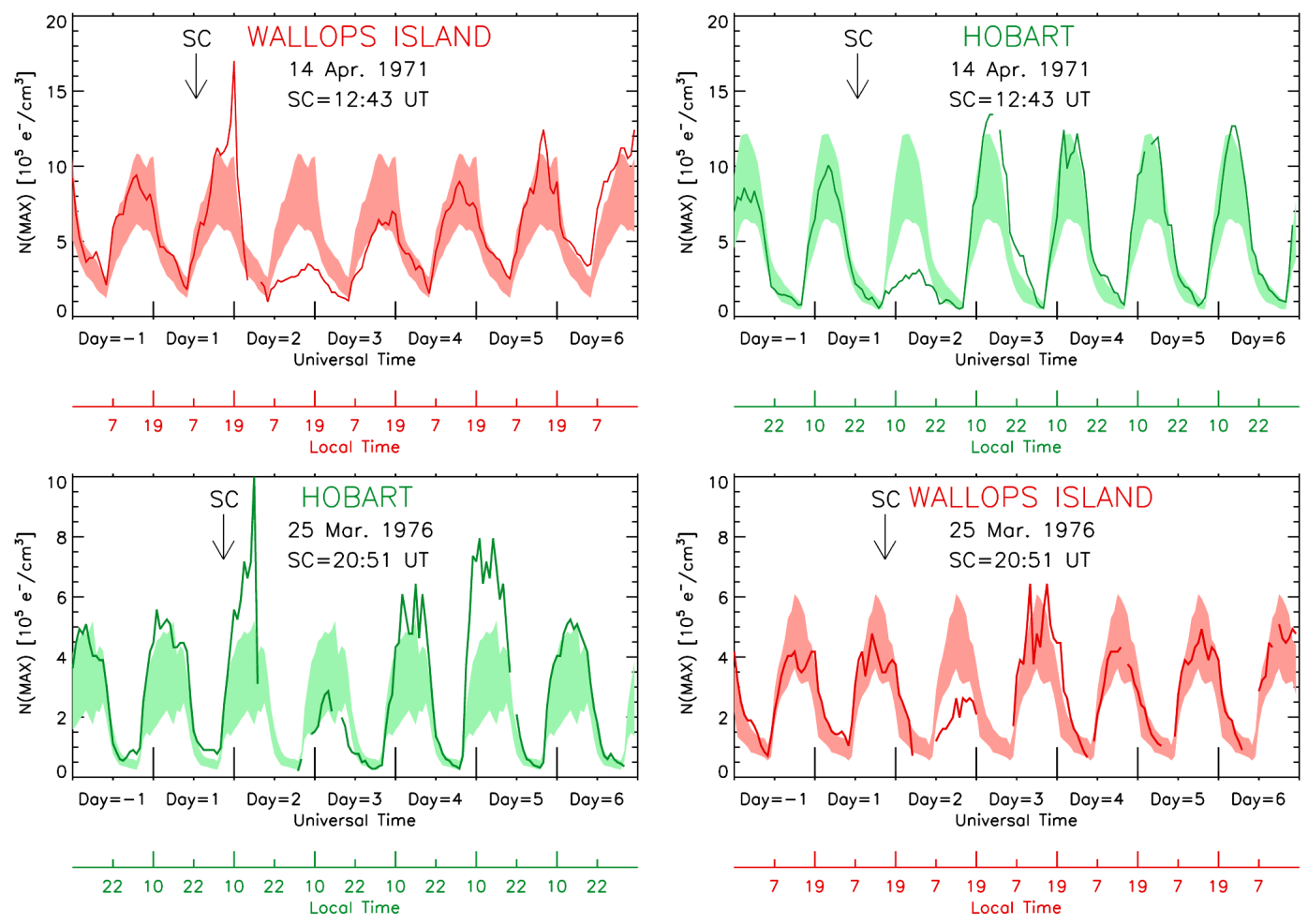

Fig. 2. Examples of ionospheric storms at Wallops Island and Hobart. The top panel illustrates an SC time that occurred during the daytime at Wallops Island and at nighttime at Hobart. The lower panel shows an example of the reverse case. Shadings give the pattern of the monthly mean with one standard deviation $( \pm \sigma)$ about that mean.

can be done. For all of these reasons, $N m \mathrm{~F} 2$ values formed from observed $f o \mathrm{~F} 2$ data constitute the parameter of choice. We note, however, that ionosonde data can suffer degradations due to the very storm effects we hope to study. With many storm periods available, however, we anticipate that "lost data" at various points during individual storms will not have a collective statistical influence upon results. We will deal with this point in the results to be shown in later sections.

Finally, Table 1 shows that the latitudes for Wallops Island and Hobart actually differ by $\sim 5$ degrees geographically and by $\sim 3.5$ degrees geomagnetically. Thus, solar production differences (ordered by solar zenith angle) and influences of auroral processes (ordered by L-shells) might have subtle impacts up our results, and these are discussed in Sect. 5.

\section{Procedure}

\subsection{Event selection criteria and case studies during a single solar cycle}

Solar cycle \#20 (officially spanning the period October 1964 to June 1976) was chosen to define analysis methods because of the validation possibility with previous studies at Wallops Island during a portion of that solar cycle (Mendillo et al., 1972). We selected geomagnetic storms that had either a sudden storm commencement (SSC) or a gradual storm commencement (GSC), collectively called the storm commencement (SC) time, rounded to the hour in Universal Time (UT). For a storm to be included in our list of events, the daily geomagnetic index $A_{p}$ had to be $\geq 30$ or $K_{p} \geq 5$ on the day of the SC or on the following day. There were 206 storms that met these requirements. The full set of storms and the indices associated with them are given at our website: www.buimaging.com/stormstudy, together with graphical results for all of the analyses conducted, only a portion of which are included in this paper.

Figure 1 summarizes solar cycle \#20 using F10.7 and $A_{p}$, and the number of storms per month meeting the criteria used. Panel (a) shows that this solar cycle had a rather weak maximum (F10.7 160 units, in comparison to $\sim 250$ units and 200 units for solar cycles \#19 and \#21, respectively). The solar minimum periods (F10.7 70 units) are typical for the baseline years before and after solar maximum in all solar cycles. The years of declining activity are the most "geo-effective" as shown in panels (b) and (c). These trends should all be kept in mind when results for ionospheric storms during different phases of the solar cycle are portrayed in Sect. 4.4. 
Table 2. Distribution of Storms by Season, Phase of the Solar Cycle, and Local Times of Storm Commencement (SC) for Wallops Island and Hobart.

\begin{tabular}{|c|c|c|c|}
\hline & Wallops Island (VA) & & Hobart (Tasmania) \\
\hline $\begin{array}{l}\text { June Solstice } \\
\text { (May, Jun, Jul, Aug) }\end{array}$ & Summer & 75 & Winter \\
\hline $\begin{array}{l}\text { December Solstice } \\
\text { (Nov, Dec, Jan, Feb) }\end{array}$ & Winter & 58 & Summer \\
\hline $\begin{array}{l}\text { Equinox } \\
\text { (Mar, Apr, Sep, Oct) }\end{array}$ & Equinox & 73 & Equinox \\
\hline Solar Minimum & & 51 & \\
\hline Solar Rising & & 28 & \\
\hline Solar Maximum & & 43 & \\
\hline Solar Falling & & 84 & \\
\hline Daytime SC events & 120 & & 107 \\
\hline Nighttime SC events & 86 & & 99 \\
\hline Summer (Day SC) & 46 & & 30 \\
\hline Summer (Night SC) & 29 & & 28 \\
\hline Winter (Day SC) & 32 & & 44 \\
\hline Winter (Night SC) & 26 & & 31 \\
\hline Equinox (Day SC) & 42 & & 33 \\
\hline Equinox (Night SC) & 31 & & 40 \\
\hline Solar Max (Day SC) & 24 & & 23 \\
\hline Solar Max (Night SC) & 19 & & 20 \\
\hline Solar Min (Day SC) & 28 & & 30 \\
\hline Solar Min (Day SC) & 23 & & 21 \\
\hline Solar Rising (Day SC) & 13 & & 15 \\
\hline Solar Rising (Night SC) & 15 & & 13 \\
\hline Solar Falling (Day SC) & 55 & & 39 \\
\hline Solar Falling (Night SC) & 29 & & 45 \\
\hline
\end{tabular}

Table 2 gives the number of storms sorted by 4-month seasons (June solstice $=$ May-August, December solstice $=$ November-February, Equinoxes = March, April, September, October), by phases of the solar cycle, and by the storm commencement (SC) times according to local time for each station, season and phase of the solar cycle.

For ionospheric data, we used hourly values in UT of foF2 from Wallops Island and Hobart, taken from the Space Physics Interactive Data Resource (SPIDR) at website http: //spidr.ngdc.noaa.gov/spidr/index.jsp. Observations for a seven day period were selected for each storm event, one day prior to the SC day, the day of SC and five days after it. If a second storm occurred during those five days, then a new storm period was defined and the earlier storm simply did not have late coverage for those hours, nor did the second storm have pre-SC coverage.

The choice of a control curve from which to compute percent departures has always been somewhat of an issue in statistical studies of storm effects. The monthly mean of the diurnal pattern of $N m \mathrm{~F} 2$ is most often used, and that is our choice as well. It has the advantage that the standard deviation $(\sigma)$ about the monthly mean is often used to describe ionospheric variability, and thus storm effects computed in this way can be seen to have a contribution to that value.
Figure 2 gives examples of two ionospheric storms observed at Wallops Island and Hobart. In each case, the shaded patterns give the $N m \mathrm{~F} 2$ monthly mean $\pm \sigma$ and the solid lines give the hourly values of $N m \mathrm{~F} 2$ for each storm period. These examples show that very similar storm effects can occur at both sites. For the 14 April 1971 event (top panels), a daytime SC at Wallops Island is followed by a classic dusk effect with a severe termination and a negative phase on the following day. At Hobart, the SC is post-sunset and the following day shows only a pronounced negative phase ionospheric storm. In the lower panels, the 25 March 1976 event shows a daytime SC at Hobart leading to a dusk effect on the SC day and a negative phase the following day, while at Wallops Island the post-sunset SC is followed by a negative-phase-only ionospheric storm. These somewhat "mirror image" patterns for day vs. night SC times during equinox storms add confidence to the notion that geophysically-equivalent sites can be identified in both hemispheres. The question of statistical consistency for many storms showing similar effects is now examined. 

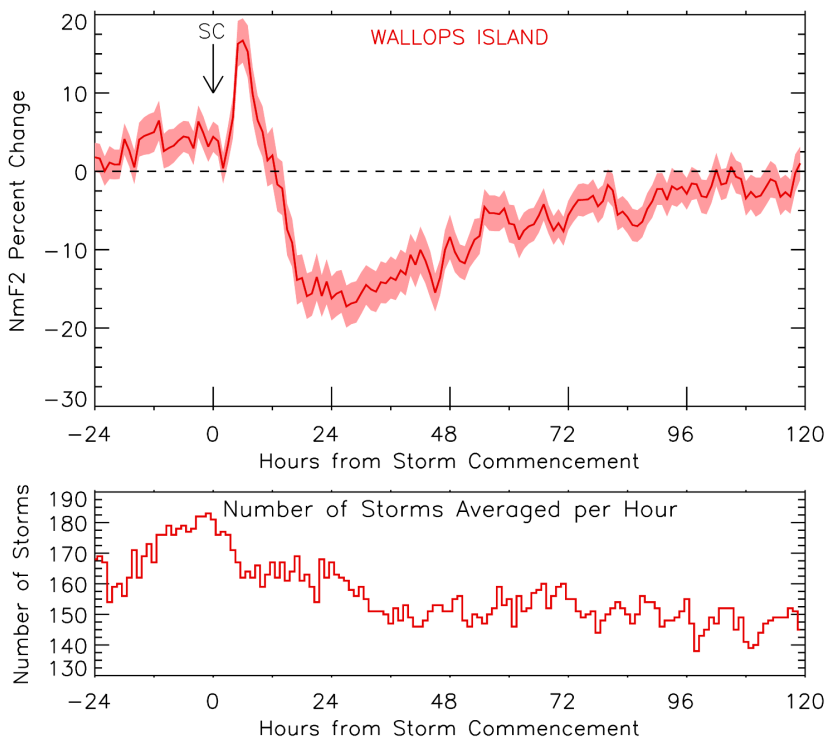

Fig. 3. Average storm-time patterns for $\Delta N m \mathrm{~F} 2(\tau, \%)$ at Wallops Island. The shading gives the error of the mean (see text) at each storm-time hour. The lower panel gives the number of storms (from the total of 206 possible) used to form the pattern given. To illustrate the difference between the standard deviation $(\sigma)$ and the error of the mean $\left(\sigma_{M}\right), \sigma= \pm 35.94 \%$ at the peak of the positive phase $(\tau=6 \mathrm{~h})$, and $\sigma= \pm 33.98 \%$ at the peak of the negative phase ( $\tau=27 \mathrm{~h}$ ). At these times, $\sigma_{M}= \pm 2.82 \%$ and $\pm 2.68 \%$, respectively.

\subsection{Formation of statistical patterns}

For this pilot study of dual hemisphere storm effects, the most direct way to compare characteristic responses at two sites is to track the disturbances according to storm time $(\tau)$, $D_{s t}(\tau, \Delta N m \mathrm{~F} 2$ in $\%)$, where the hourly values of percent deviation are computed from their corresponding monthly means. Thus, percent-change time sequences are simply averaged to form $<D_{s t}(\tau, \%)>_{i}$, where $\tau$ is at hourly intervals from the UT of the SC, and $i$ represents sample size, e.g., the number of storms in winter months, or the number of storms during solar minimum years, etc. This type of analysis was first introduced for the study of geomagnetic storms, and then popularized for use with ionospheric storms by Matsushita (1959) with ionosonde data, and later for TEC data by Hibberd and Ross (1967) and Mendillo (1971).

\section{Results}

\subsection{All storms}

Figures 3 and 4 give the average storm time patterns for all storms at Wallops Island and Hobart. The top panels show by shading the errors of the mean $\left(\sigma_{M}\right)$ for each hour, where $\sigma_{M}=\sigma /(n)^{1 / 2}$, with $\sigma=$ the standard deviation about the mean and $\mathrm{n}$ is the number of data points used to form the
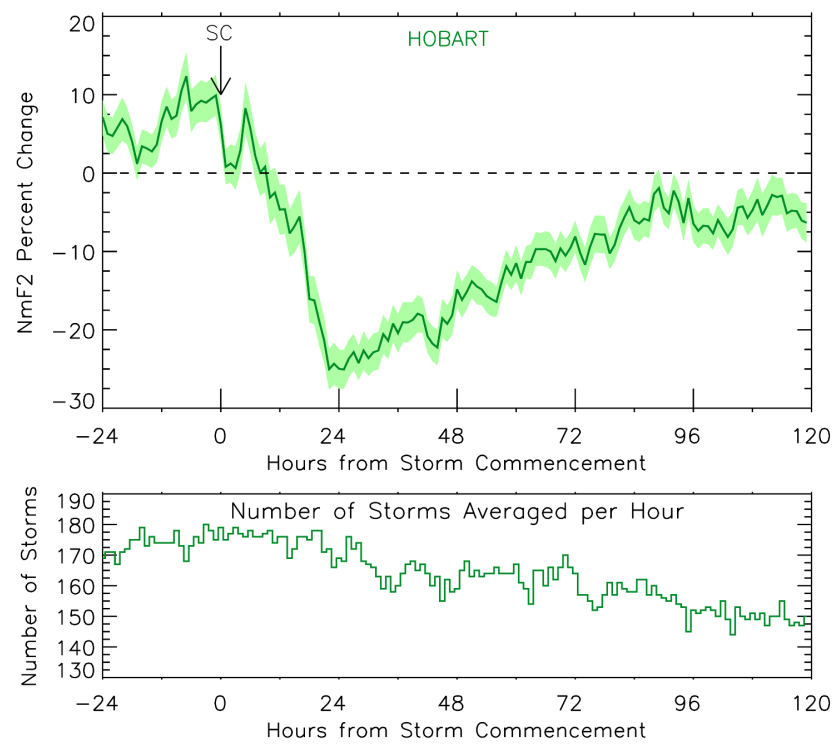

Fig. 4. Average storm-time patterns for $\Delta N m \mathrm{~F} 2(\tau, \%)$ at Hobart. The shading gives the error of the mean (see text) at each stormtime hour. The lower panel gives the number of storms (from the total of 206 possible) used to form the pattern given. To illustrate the difference between the standard deviation $(\sigma)$ and the error of the mean $\left(\sigma_{M}\right), \sigma= \pm 42.53 \%$ at the peak of the positive phase $(\tau=5 \mathrm{~h})$, and $\sigma= \pm 31.69 \%$ at the peak of the negative phase $(\tau=25 \mathrm{~h})$. At these times, $\sigma_{M}= \pm 3.29 \%$ and $\pm 2.48 \%$, respectively.

mean Thus, while $\sigma$ describes the breadth of values that form the mean, $\sigma_{M}$ describes the rigor of the same mean value being obtained from independent sets of such data (Taylor, 1997). The lower panels show the number of storms used to compute those patterns. The fact that the total number of storms decreases for late storm-times simply results from the occurrence of subsequent storms, i.e., it does not indicate a problem of lost data for several days within the recovery phase of many individual storm. The maximum number of storms in each average is about 180 out a possible 206 events, a very reliable sample size. Over this 11 -year period, data outages (whether due to a storm itself, or some local operational or instrumental issues) at Wallops Island or Hobart are about the same, giving confidence that no hidden biases remain from those possible effects.

The results from Figs. 3 and 4 are over-plotted in Fig. 5 (with the uncertainty level shadings suppressed to facilitate comparisons). These two curves offer a robust statistical portrayal of the concept of geophysically-equivalent sites, reinforcing the suggestions of such equivalence from the two case studies illustrated in Fig. 2. Thus, for the sub-auroral Flayer ( $\sim$ midlatitudes), ionospheric storms have a short positive phase, a longer negative phase, and a return to prestorm conditions many days after the storm commencement (as first described statistically by Matsushita, 1959). While individual storms would be expected to show characteristic 


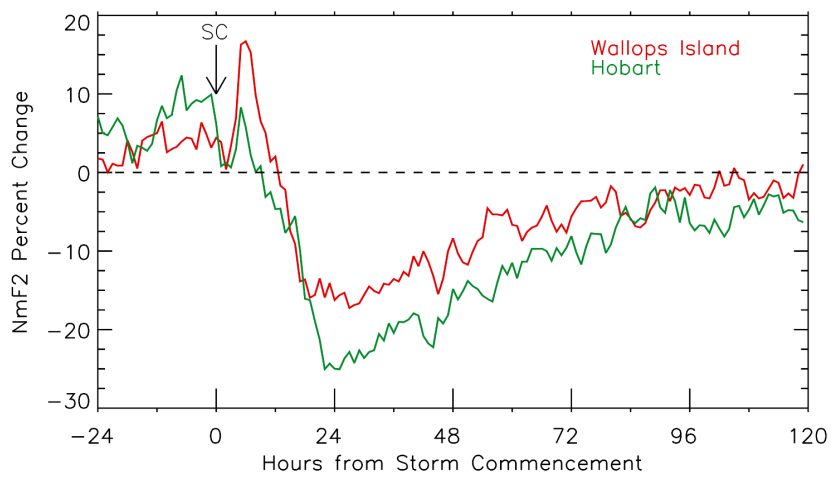

Fig. 5. A comparison of the average patterns from Figs. 3 and 4. Note that the pre-storm pattern does not span zero, a feature seen in all such analyses since Matsushita (1959) that arises from the monthly mean containing so many negative phase days.

differences due to well known effects (e.g., season being the dominant one for hemispheric comparisons), there is a coherence of response in Fig. 5 that attests to the stability of geophysical systems under stress from external forcings. As with human behavior, each and every case is different, but stereotypical patterns emerge that provide meaningful information because so many cases conform to a pattern. Yet, there are small differences: the average positive phase at Wallops Island is almost twice that at Hobart, and the negative phase is slightly deeper and longer-lived at Hobart.

In the following sections, we divide the total sample of 206 storms into statistically reliable subsets to search for differences, strong or subtle, that may be hidden within the remarkably small differences shown in Fig. 5 .

\subsection{Seasonal effects}

As shown in Table 2, the 206 storms have an acceptable distribution between equinox, June solstice and December solstice months. Since the 73 storms during equinox periods refer to the same storm in each hemisphere, one might anticipate that storm effects would agree best during those periods. The 75 summer storms observed at Wallops Island are, of course, the 75 winter storm events at Hobart; similarly, the 58 winter storms at Wallops are the same events that form the 58 summer storms at Hobart. Figure 6 gives the stormtime patterns for these periods. In the top panel, the equinox cases show very strong correlations between the phases at both sites, with the transitions between positive and negative phases particularly well ordered in time and magnitude. The magnitude of the positive phase at Wallops is about twice that at Hobart, while the negative phase values are slightly deeper at Hobart. Recall, however, that errors of the mean, as shown in Figs. 3 and 4, would be slightly larger for these smaller sample sizes.

The middle panel in Fig. 6 gives results for summer storms. The major difference is the lack of a statistical pos-
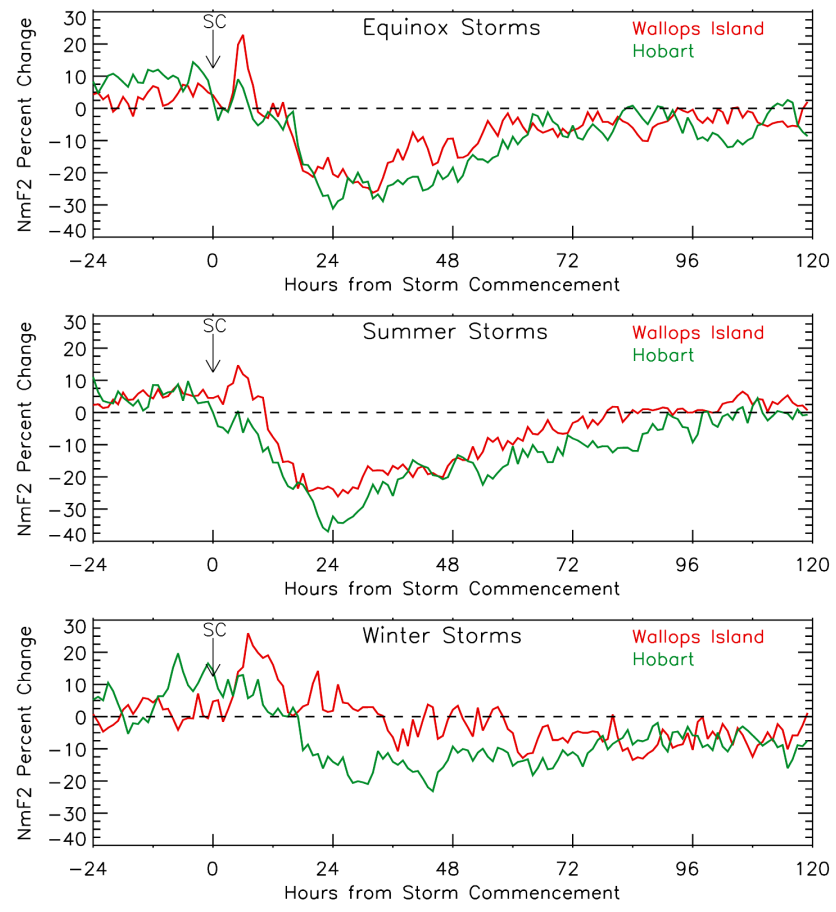

Fig. 6. Average storm-time patterns for Wallops Island and Hobart sorted by season. See Table 2 (or text) for the number of events in each season.

itive phase at Hobart during summer storms. The negative phases are in good agreement, with the depth of the depletions again larger and more persistent at Hobart. For winter storms (third panel), both sites have a positive and negative phase, with the former of longer duration at Wallops and the latter of deeper magnitude at Hobart. The conclusion we draw from Fig. 6 is that the all-storm patterns in Fig. 5 are so consistent because the influence of season is essentially consistent at each site. Specifically, the equinox cases are clearly similar in all respects, while the summer storms are dominated by negative phase effects at both sites. Winter storm effects studied in the Northern Hemisphere have long been known to have prolonged positive phases and often minor (or absent) negative phase (Mendillo, 2006). This appears not to be the case in the Southern Hemisphere where the bottom panel shows two clearly separated phases at Hobart.

There are two main results from Fig. 6 that need further attention. The first is the slight difference between summer vs. winter effects at both sites, and the second is the un-anticipated absence of a positive phase from the statistical analysis of 58 storms during summer months at Hobart. We defer the first to the discussion section, and proceed here with the possibility of this pattern emerging from the distribution of the local times (as recorded at Hobart) of the storm commencement (SC) times in UT. Recall from Fig. 2 (top right panel) that for an $\mathrm{SC}$ after sunset, the F-layer at Hobart 

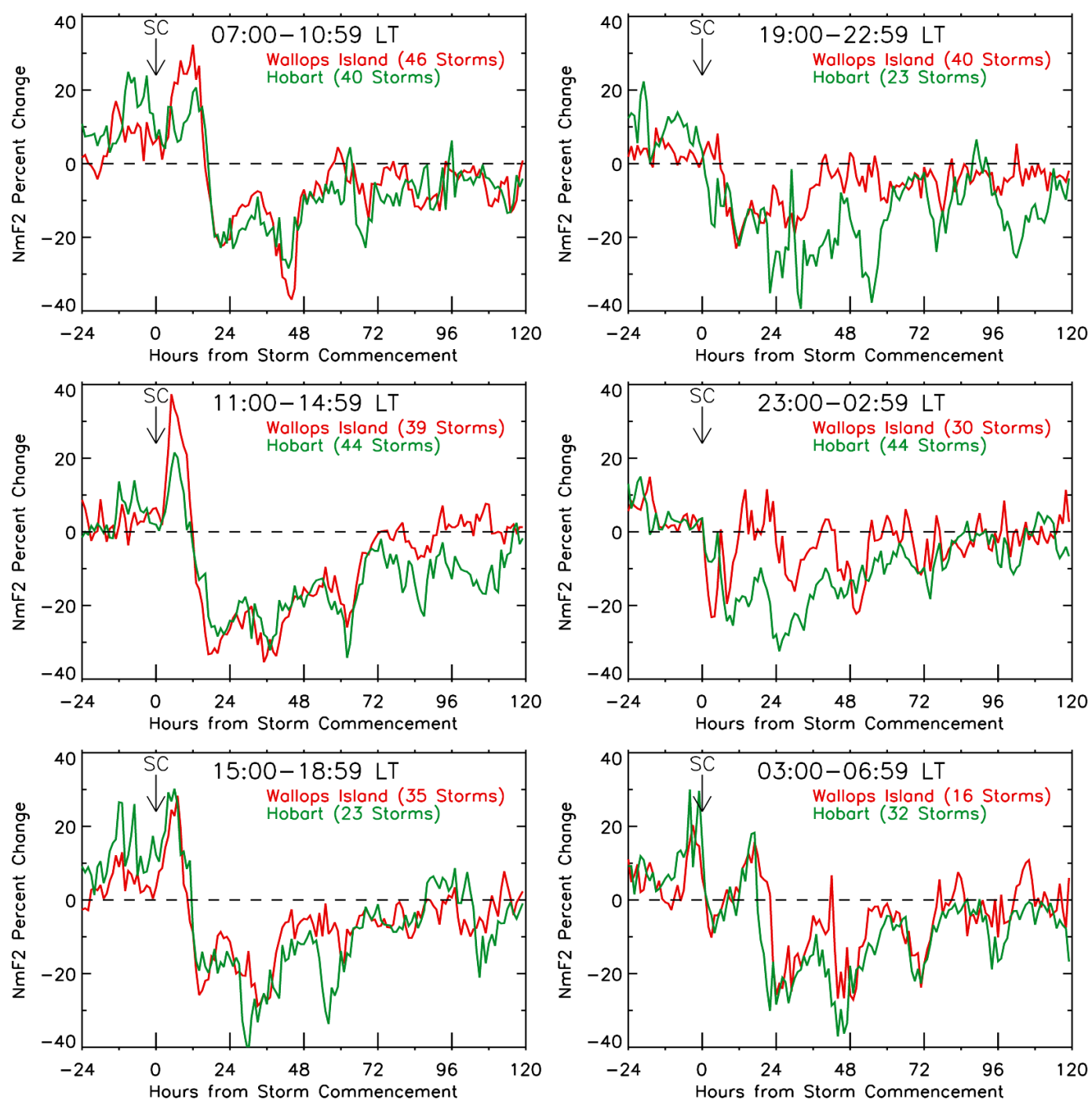

Fig. 7. Average storm-time patterns for Wallops Island and Hobart sorted by the local time (LT) of the storm commencement. The panels on the left give daytime SCs in 4-h windows; panels on the right give nighttime SC results.

went directly into a negative phase storm. Is this a pattern that is maintained in statistical treatments? Does it account for the apparent weak positive phase at Hobart for all storms (Fig. 5)? Could the 58 summer solstice events have a very unequal distribution of LTs that led to this effect as well?

\subsection{Effects due to local time of the storm commence- ment}

The interplay between positive and negative storm effects at midlatitudes relates directly to the time constants for the appearance and persistence of three processes: (a) electric fields of magnetospheric origin, (b) equatorward winds from auroral heating, and (c) the $\mathrm{O} / \mathrm{N}_{2}$ changes due to auroral heating. Effects (a) and (b) cause positive phases in $\mathrm{NmF} 2$ and TEC, while (c) produces their negative phases. Studies of these time-line relationships date at least to the pioneering work of Rishbeth (1963) for NmF2 and to Mendillo (1973) and Balan and Rao (1990) for TEC.

With 206 storm periods available during solar cycle \#20, it is possible to conduct a comprehensive statistical examination of such effects at geophysically comparable sites. Balan and Rao (1990) examined 63 storms from the Wallops Island area only, and for a subset of years (1968-1972) for the same solar cycle, and thus we are fortunate to be able to validate our findings with theirs for the Northern Hemisphere. The results appear in Fig. 7. The SC times have been divided into six 4-h LT windows, with storm-time patterns derived from only those subsets of storms at each site. The daytime SC results (left panels) show a very consistent pattern between the hemispheres, with clear and well defined positive and negative phases following the storms' onsets. For the storms that 

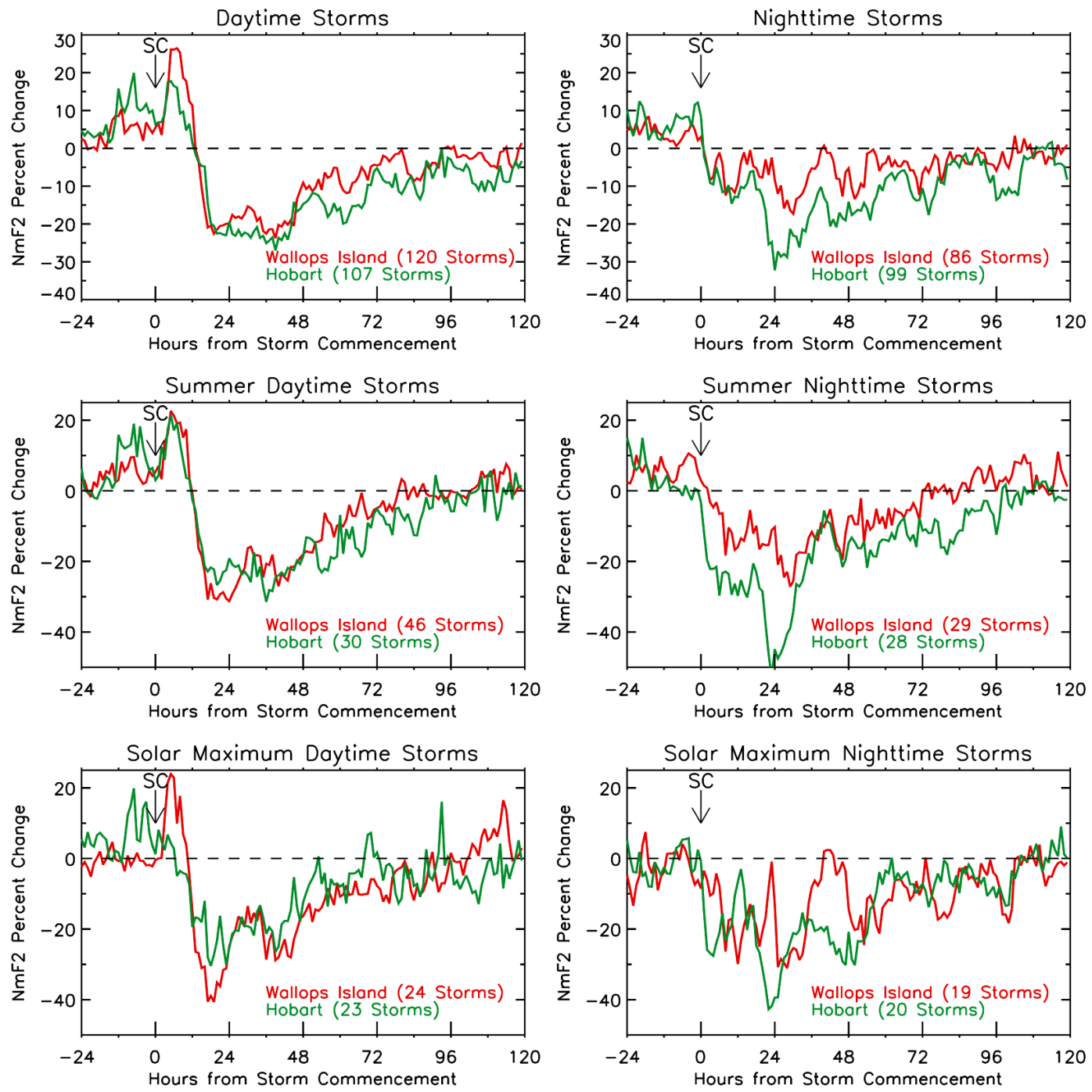

Fig. 8. Comparison of average storm-time patterns at Wallops Island and Hobart for day versus night SC times. Panels (a) and (b) describe the total sample of storms, panels (c) and (d) describe storms during local summer months, and panels (e) and (f) storms during solar maximum years.

began during nighttime hours at each location (right panels), the patterns are far less coherent. Nighttime SCs can lead to either delayed-positive-phase (DPP) storms or no-positivephase (NPP) storms, as described in Mendillo (1973) and Lanzerotti et al. (1975). The patterns for nighttime SCs at Hobart give the clear impression that negative phase effects dominate (i.e., NPP storms are more likely), implying that the effects of auroral heating might dominate over persistent electrodynamics or long-lived equatorward winds in the thermosphere.

An important point to note from Fig. 7 is that the numbers of storms used to form the left panels (i.e., daytime SCs) are comparable for each 4-h block and for each site. This is not the case for the nighttime storms. There are far fewer storms that begin in the post-sunset hours at Hobart and far fewer that begin in the pre-dawn hours at Wallops Island. The total for daytime vs nighttime storms at Wallops Island (120 day vs. 86 night) is a noticeably larger difference than occurs at Hobart (107 day vs. 99 night). The effect is to favor daytime storm commencements at Wallops Island, and thus this fact offers no support to the notion that positive phase storms are less prominent at Hobart simply because most of the storms during solar cycle \#20 began there at night. This is illustrated in Fig. 8 where the top panels divide the full data sets into 12-h day versus 12-h night SC times. Panel (a) is thus the average of all the left hand panels of Fig. 7, and panel (b) the average of all the right hand panels. The clear occurrence of positive phase storms at both sites (with Wallops Island's stronger than Hobart's) again appears in panel (a); they also have remarkably similar onsets to the negative phase. In 

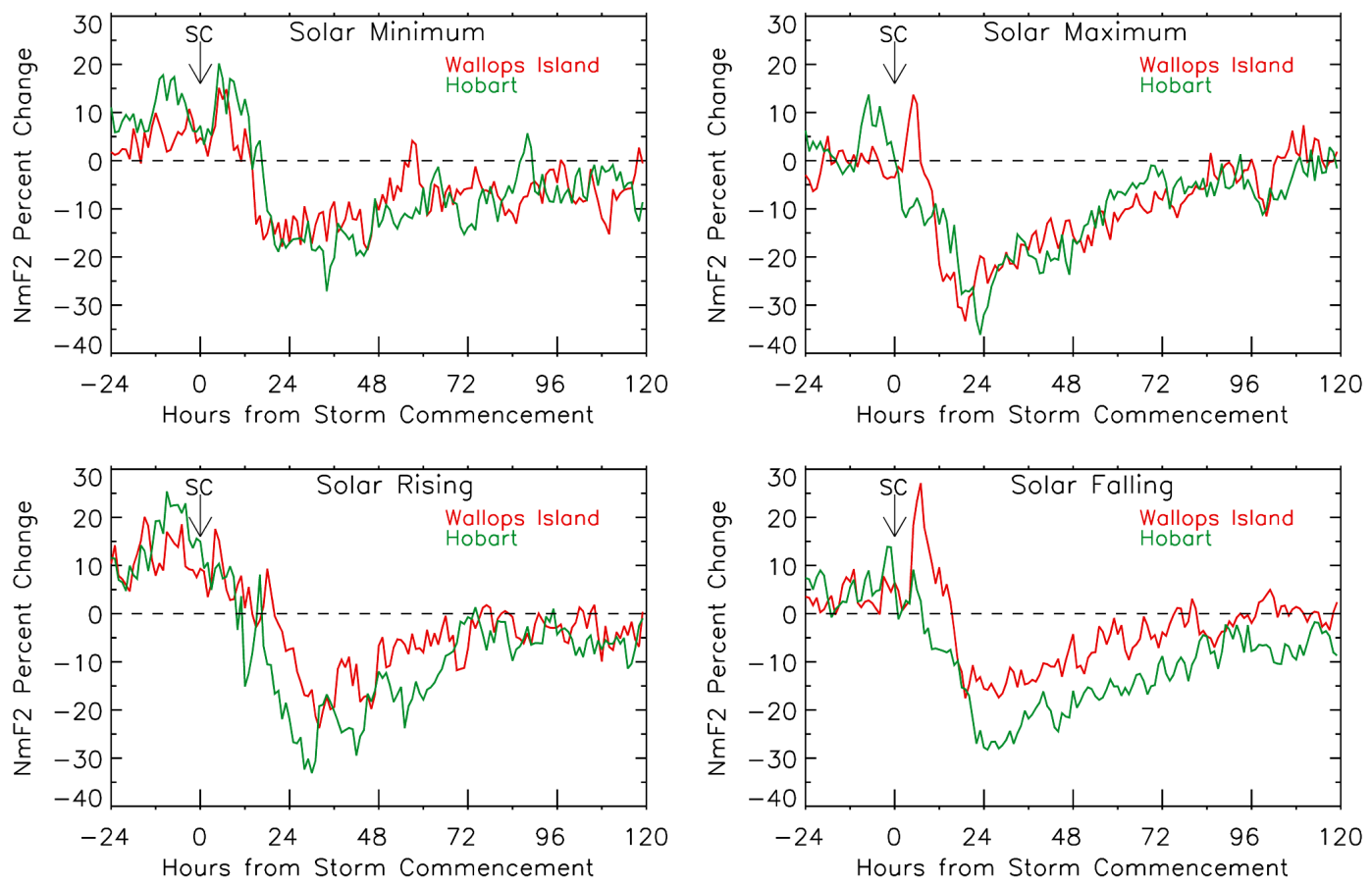

Fig. 9. Average storm-time patterns for Wallops Island and Hobart sorted by phases within solar cycle \#20 as defined in Fig. 1. Panels (a) and (b) give results for solar minimum and maximum periods, while panels (c) and (d) give results for the rising and falling portions of the solar cycle.

panel (b), the nighttime SCs produce produce patterns that are similar for the intial $\sim 12 \mathrm{~h}$, but then the Hobart storms have a more uniformly stronger negative phase.

For the subset of summer storms, however, we find a difference in comparison to the total sample size results in panels (a) and (b). Panel (c) shows extremely similar effects for daytime SC times, for both positive and negative phases. Panel (d) shows nighttime SCs to provoke significantly sharper transition to the negative phases at Hobart. Thus, the statistical lack of a positive phase for summer storms at Hobart is related directly to the fact that its nighttime SC storms dominate over a similar number of daytime $\mathrm{SC}$ storms (i.e., producing the no-positive-phase results in Fig. 6 (middle panel). The bottom panels in Fig. 8 refer to solar cycle phase effects discussed next.

\subsection{Effects during different phases of the solar cycle}

A cornerstone of solar-terrestrial-physics has been the goal of understanding how the waxing and waning of solar activity, with an approximate 11-year periodicity, governs the response to perturbations upon and within the geospace system. While the birth of the space age in 1957-1958 coincided with one of the largest peaks in solar activity, satellites designed for comprehensive space physics missions did not have their impact until the following solar cycle (\#20, 19641976), the period chosen for this study. As shown in Fig. 1, the solar flux parameter F10.7 portrays the typical pattern of a steeper rise than decline in solar activity. We have divided this cycle into four phases: Minimum (onset in October 1964 through 1965, plus 1975 through June 1976), Rising (1966 and 1967), Maximum (1968 through 1970) and Declining (1971 through 1974). Geomagnetic activity, as represented by the daily index $A_{p}$, does not following this pattern closely, leading to the discovery that coronal holes are the dominant cause of geomagnetic activity during the declining phases. In panel (c) of Fig. 1, the number of storms meeting the selection criteria for this study, similarly, does not show a oneto-one coherence with F10.7, but (obviously) more so with panel (b).

To examine if the ionosphere responds differently to storm within each of these phases, we show in Fig. 9 the solar cycle effects at each station. For solar minimum storms, panel (a) shows that the responses at Wallops Island and Hobart are very consistent in both magnitudes and durations of the positive and negative phases. For storms during solar maximum years, panel (b) shows that both stations have nearly identical negative phases, with both about twice the depth found in panel (a) for solar minimum storms. The positive phases, however, are very different. Specifically, there is no positive phase at Hobart, while the classic patterns of a short positive phase followed by a negative phase occurs at Wallops Island.

Given that the statistical absence of a positive phase for summer storms at Hobart resulted from the day versus night SC local time effect (Fig. 8c, d), we performed the same 
analysis for solar maximum storms. These results are shown in panels (e) and (f) of Fig. 8. While there are slightly more daytime SCs at Hobart (23 day vs. 20 night), a condition expected to favor positive phase effects, the pattern obtained in panel (e) offers only an extremely minor initial positive phase. We conclude, therefore, that the absence of an average positive phase for solar maximum storms in the Southern Hemisphere is a statistically robust finding.

For the rising vs. falling portions of the solar cycle, panels (c) and (d) in Fig. 9 show that positive and negative phases are present at both locations. For solar rising years, the positive phase patterns are essentially the same at Wallops Island and Hobart, while the negative phase is again a bit deeper and longer lived at Hobart. The most interesting results appear in panel (d) for storms during years of solar cycle decline. Well-defined phases appear in both hemispheres, with the positive phase at Wallops Island three times larger than at Hobart. The negative phase is twice as deep at Hobart, and has a recovery time at least two days longer than found at Wallops Island. Possible sources of these distinctive patterns in Fig. 9 are treated in Sect. 5.

\subsection{Effects due to storm severity}

In his pioneering study of ionospheric storms, Matsushita (1959) examined how changes in $N m \mathrm{~F} 2$ depended upon the strength of a geomagnetic storm. A total of 109 storms were used with 51 having $A_{p}>50$ (called strong storms) and 58 having $A_{p}<50$ (called weak storms). The responses observed at ionosonde stations were averaged in zones of comparable latitudes, with both hemispheres combined. Here we show hemispherically separated responses as yet another way to examine geophysically-equivalent sites. Figure 10 gives the distribution of the most commonly used geomagnetic index to characterize storms: $K_{p}$. As described in Sect. 3.1, our storm selection criteria eliminated weak storms, i.e., those that did not have $A_{p} \geq 30$ or $K_{p} \geq 5$ for at least one day of a storm. Thus, some $(\sim 3 \%)$ of our 206 storms had $A_{p}>30$ but $K_{p}<5$, and well as the reverse case. Using $K_{p}$ to characterize severity, we divide our 206 storm periods into three categories: Moderate $\left(K_{p} \leq 6\right)$, Strong $\left(K_{p}=7\right)$, and Very Strong $\left(K_{p}=8-9\right)$. In this way, $\sim 10 \%$ of our events (20 storms) are very strong, $\sim 20 \%$ are strong (35 storms), and $\sim 70 \%$ are moderate (151 storms). The storm-time patterns at Wallops Island and Hobart for these three subsets of storm magnitude are given in Fig. 11.

The message from Fig. 11 is an assuring one. The most long-lived component of an ionospheric storm, its negative phase, increases in depth as the strength of the geomagnetic storm increases. Thus, for the $70 \%$ of storms classified as moderate, the negative phase at Wallops Island is $-10 \%$, increasing to $-20 \%$ for strong storms, and $-60 \%$ for the very strong storms. At Hobart, the levels are $-20 \%$ for moderate storms, $-30 \%$ for strong storms, and $-50 \%$ for the very strong storms. As in other analyses, the negative phase at Ho-

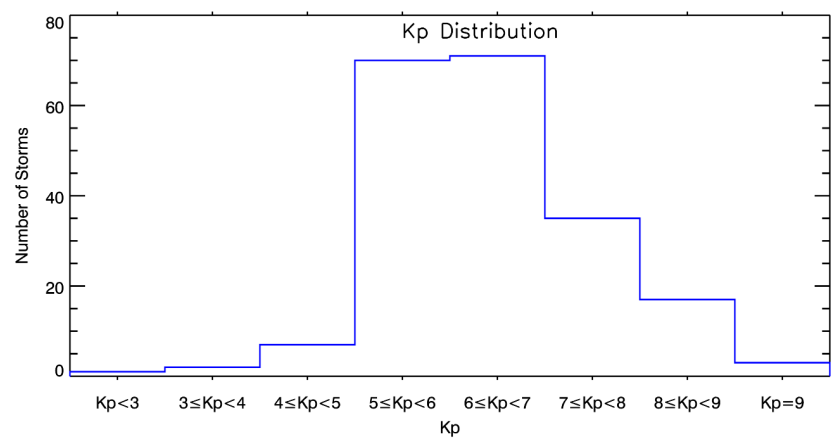

Fig. 10. The distribution of storms selected for this study according to the maximum value of the $K_{p}$ index during each of the 206 storm events. Three groups are formed with moderate storms $\left(K_{p} \leq\right.$ 6) having 151 events $(\sim 70 \%)$, strong storms $\left(K_{p}=7\right)$ having 35 events $(\sim 20 \%)$ and very strong storms $\left(K_{p}=8-9\right)$ having 20 events $(\sim 10 \%)$.

bart is always a bit stronger at Hobart than at Wallops Island, except here for the top $10 \%$ of storms with $K_{p}=8-9$. The fact that average depletions reach -50 to $-60 \%$ (recalling that $-100 \%$ is impossible) attests to the extraordinary effect a disturbed thermosphere can impose upon the ionosphere. Yet, the recovery of these "super-storm" negative phases is relatively fast, i.e., at $\tau=+48 \mathrm{~h}$ their patterns are essentially indistinguishable from less severe storms. Perhaps most curious, given the attention given to 'dusk effect' enhancements and SED patterns during cases studies of super-storms, is the negligible average positive phases at both locations during the very strongest storms. The statistical robustness of these effects awaits further analyses of storms during other solar cycles.

\section{Discussion}

\subsection{Overview: pre-conditioning by seasonal processes}

The sub-auroral ionosphere, and broadly speaking the midlatitude ionosphere, has a distinctive response to geomagnetic storms. Electrodynamics, thermospheric winds and composition changes are all possible contributors of potentially similar magnitudes (Burns et al., 2007). The study of ionospheric storms at geophysically- equivalent sites, as initiated here, offers the opportunity to assess the blending and phasing of mechanisms and, perhaps, advance our understanding of the ambient ionosphere as well. This is possible because ionospheric storms provoke changes in a few days that mimic changes in the ambient ionosphere that occur over far greater time spans, e.g., with seasons or phases of the solar cycle.

To begin that discussion, a seemingly obvious statement can be made: The absolute magnitude of an ionospheric perturbation at midlatitudes depends on the amount of plasma 

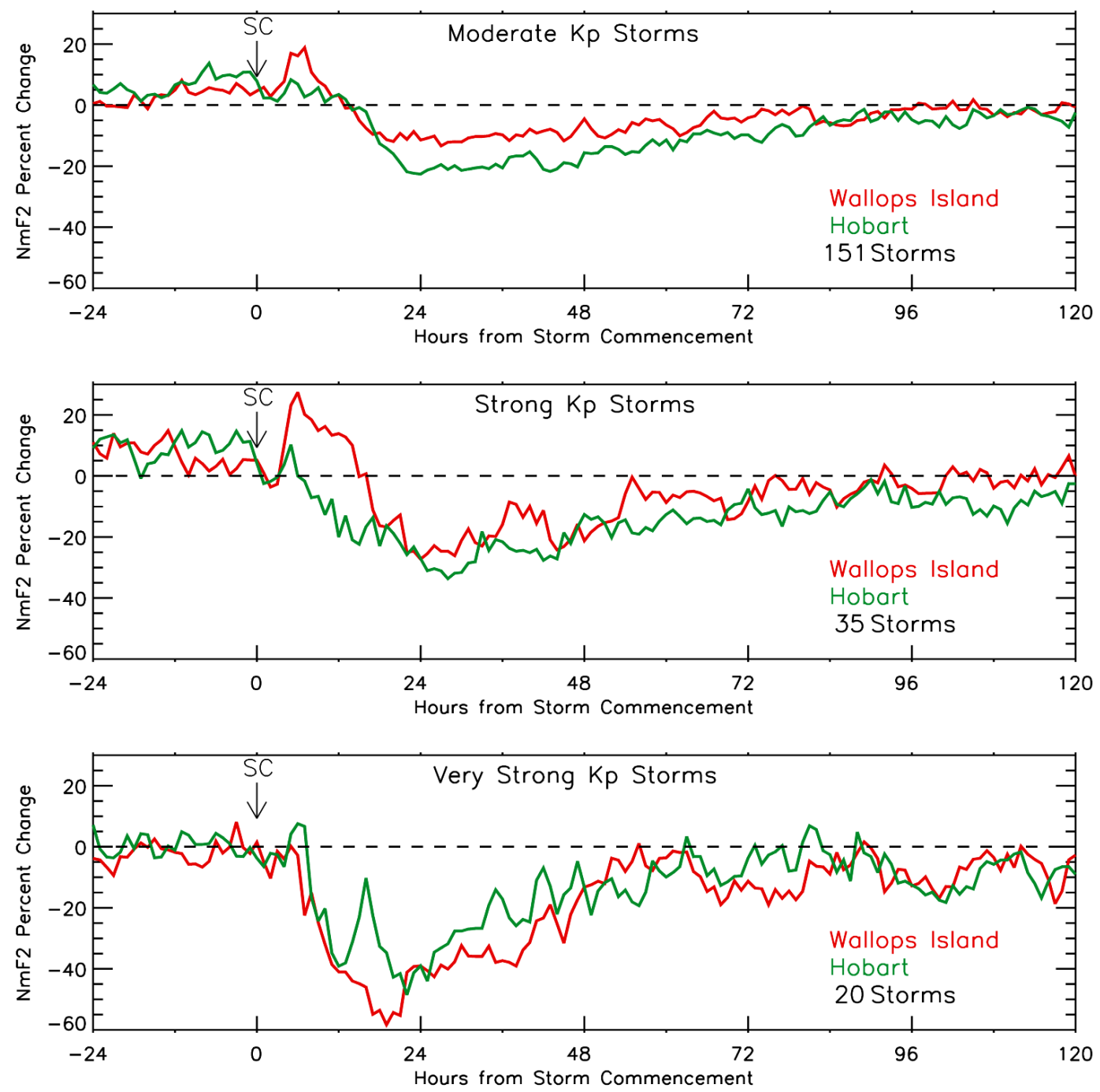

Fig. 11. The average storm-time patterns for $N m \mathrm{~F} 2$ for moderate, strong and very strong storms as observed at Wallops Island and Hobart.

existing prior to the onset of a disturbance. Thus, large dusk effects (SED-type disturbances) occur by virtue of there being a very large amount of plasma in the pre-sunset ionosphere upon which mechanisms act. Large negative phases result from enhanced loss of robust levels of ambient plasma, thus making daytime depletions impressive, while diminutions of the nighttime trough are hardly noticed (though their percentage changes can be large). The fact that the undisturbed thermosphere-ionosphere system exhibits strong seasonal effects at midlatitudes therefore sets the stage for how the F-layer will respond to perturbations (Duncan, 1969; Fuller-Rowell et al., 1996). For example, in the Northern Hemisphere, there is the well-known seasonal anomaly for which daytime values of F-layer $N m \mathrm{~F} 2$ or TEC in winter exceed those in summer. Thus, for ambient conditions that favor production over loss due to higher $\mathrm{O} / \mathrm{N}_{2}$ ratios (e.g., during winter months), storm-time perturbations simply am- plify that effect (e.g., the positive phase of storms is larger in winter than in summer, as shown in Fig. 6). In summer, the F-layer is dominated by thermospheric loss processes (lower $\mathrm{O} / \mathrm{N}_{2}$ ratios) that result in the weakest F-layer of the year, and storms simply amplify that effect producing relatively weak positive phases but the most severe negative phases of the year (Fig. 6). Thus, in the Northern Hemisphere, there is a strong coherence between seasonal effects and storm effects.

Is this true also in the Southern Hemisphere? As shown in Fig. 6, the positive phase at Hobart is prominent during winter and equinox storms, but it is absent in summer storms. For the negative phase, the deepest depletions occur during summer storms and the weakest during winter storms. Thus, again, we have coherence between seasonal effects and storm effects. Indeed, recent state-of-the-art simulations for a December storm period had significant asymmetric enhancements between the two hemispheres (Lei et al., 2008). One 
must note, of course, that ambient photochemical conditions might have nothing to do with seasonal storm differences, i.e., the perturbation mechanisms themselves could be seasonally unique (e.g., processes that cause positive storm effects are just weaker in summer), though we are unaware of any evidence supporting such a hypothesis.

\subsection{Pre-conditioning by hemispheric processes}

In our comparisons of storms at equivalent geophysical sites in both hemispheres, two inconsistent patterns were found, i.e., for storms in summer months (Fig. 6b) and during solar maximum years (Fig. 9b). For both conditions, Hobart shows no positive phase while Wallops Island does. Summer storms also have a negative phase at Hobart that is noticeably deeper and longer-lived than found at Wallops Island (Fig. 6b). The influence of the local time of the SC was found to be a significant cause of the differences found during summer storms (Fig. 8c, d), but not during solar maximum storms (Fig. 8e, f). To discuss how these two effects might also be related to preconditions in the F-layer, we show in Fig. 12 the seasonal averages of $N m \mathrm{~F} 2$ vs. LT for the four summer months and four winter months at each station, formed from the ionosonde data taken during the three years of solar maximum shown in Fig. 1. Clearly, the summer diurnal patterns are remarkably similar in panel (a), a finding that reinforces the concept of geophysically-comparable sites actually existing (i.e., the small differences in the latitudes of the two stations in Table 1 do not seem to cause noticeable latitude effects). However, the winter patterns in panel (b) are not the same. That is, the seasonal anomaly (Winter F-layer $>$ Summer F-layer) is stronger in the Northern Hemisphere, as their ratios show in panel (c). Another way of expressing this fact is the socalled "seasonal asymmetry" in $N m \mathrm{~F} 2$ that has been studied in detail by Rishbeth and Mueller-Wodarg (2006), and in its TEC characteristics by Mendillo et al. (2005). Whether averaged over entire hemispheres or in N-S station pairs, the F-layer of the Earth's ionosphere is simply more robust in December than in June, and by about $30 \%$. This asymmetry is far above that possible from solar irradiance changes due to the Earth's slightly elliptical orbit (with perigee in December). This and several other mechanisms were explored in Rishbeth and Mueller-Wodarg (2006), with no firm solution found. Could the purely hemispheric difference (as opposed to seasonal difference) in the terrestrial ionosphere under average conditions be further enhanced during storms? For example, could electrodynamical processes that cause the typical dusk effect enhancements in the Northern Hemisphere be fundamentally weaker in the Southern Hemisphere? Could auroral heating effects that enhance meridional winds and cause the composition changes responsible for the negative phase be fundamentally different for equivalent seasons in each hemisphere?

These are topics that go beyond the scope of this paper, if only for the reason that a single pair of stations has
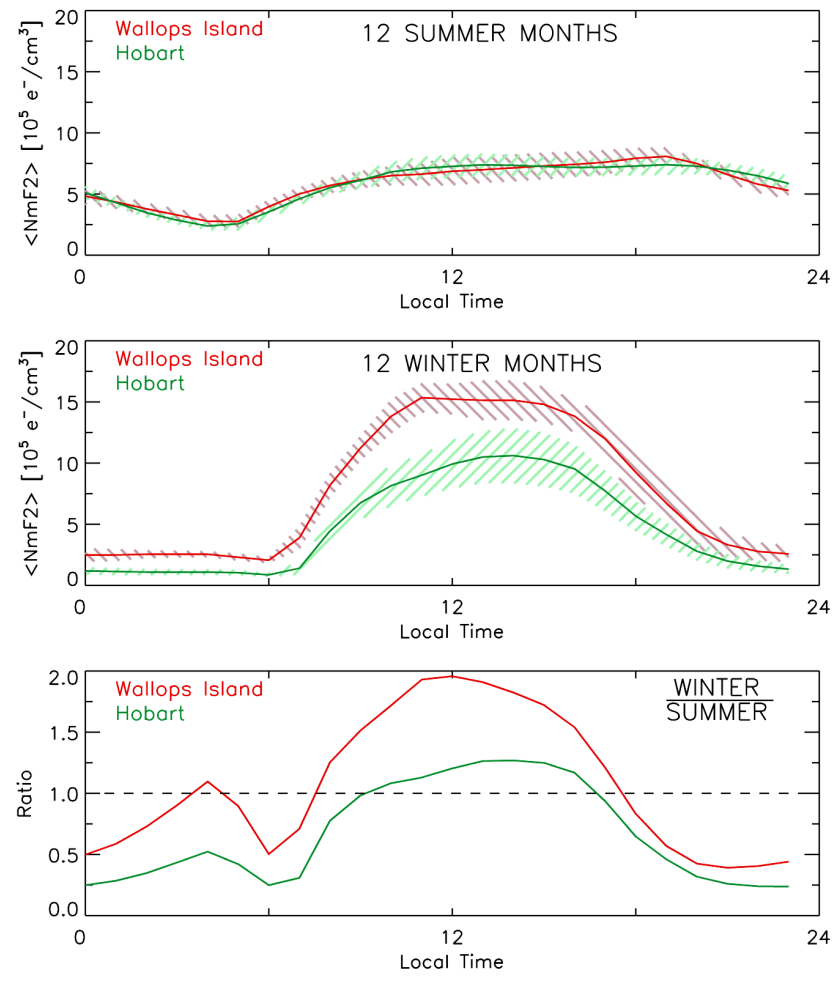

Fig. 12. Comparisons of average conditions for summer and winter months at Wallops Island and Hobart during solar maximum years. Panel (a) gives the average diurnal pattern formed from the MayAugust (Northern Hemisphere summer) months of 1968-1970 at Wallops Island in comparison to the average diurnal pattern from the November-February (Southern Hemisphere summer) months of 1968-1970 at Hobart. Panel (b) gives the average patterns for the reversed cases of winter months at Wallops Island and Hobart. Panel (c) gives the ratio of Winter/Summer patterns at each station to characterize the difference in seasonal anomaly magnitudes in each hemisphere, called the hemispheric asymmetry.

been analyzed and only during a single solar cycle. Yet the topic is one being addressed by modelers seeking correct input for global models of the coupled magnetosphereionosphere-thermosphere system. To date, the focus has been on the seasonal differences seen in "hemispheric power input" (e.g., Emery et al., 2008, 2009; Ridley, 2007, and references therein). The contributions from electrons and ions are different within a given season and that difference changes with season. To fully understand the relationships between seasonal and hemispheric effects, at least three processes need to be explored: (1) Are the hemispheric power input magnitudes for a given season different in each hemisphere? (2) Are the plasma convection velocities (and therefore Joule heating) different in each hemisphere separate from seasonal effects? (3) Do the spatial domains of auroral input extend slightly more equatorward in one of the hemisphere, i.e., do the statistical ovals reach lower magnetic latitudes (say, at midnight) near Hobart vs. near Wallops 
Island? Can studies, such as those conducted by StenbaekNielsen and Otto (1997) and Barth et al. (2002), be used to test these ideas? (4) Separate from auroral input, does the solar wind coupling with the geomagnetic field (known to have equinoctial maxima) have hemispheric differences as well? Gasda and Richmond (1998) have linked longitude effects with hemispheric variations. Could the unique $\boldsymbol{B}$-field geometry associated with the $\sim 70 \mathrm{~W}$ American zone meridian (with its South Atlantic Anomaly, SAA) somehow result in enhanced IMF $B_{y}$ coupling to the magnetosphere and/or the penetration of magnetospheric electric field to midlatitudes, with no such effect in the Australian sector where the dipole tilt is the same, but there is no counterpart to the SAA? These questions ask, in effect, "Do storm-time inputs launched by the solar wind provoke slightly different responses in each hemisphere because ambient processes (not seasons) have different sensitivities to them, and/or that the spatial locations of magnetospheric input are different?"

Returning to the concept that short-lived storm effects might help to explain longer-lived morphology patterns in the ambient ionosphere, one can move beyond simply calling any effect that does not conform to Chapman theory an anomaly. Thus, could the possible hemispheric differences in magnetospheric coupling described above also be causes of the annual asymmetry that pre-conditions each hemisphere for non-identical patterns of ionospheric storms? In their comprehensive treatment of the relationship between the seasonal anomaly and the hemispheric asymmetry of the Flayer, Rishbeth and Müller-Wodarg (2006) offered two suggestions that bear on the speculations above:

1. Concerning the different morphologies of the geomagnetic field: "The asymmetry might be due to some differences between Northern and Southern Hemispheres, rather than a difference between the northern and southern solstices."

2. Concerning thermospheric circulation: "The annual asymmetry might be due to different patterns of upwelling and downwelling, and thus of neutral composition, in the two hemispheres."

The alternative for pre-conditioning from solar wind and auroral inputs is coupling from below. The recent study by Qian et al. (2009) explored how strong seasonal variations of eddy diffusion in the mesopause region (larger during solstices than equinoxes) can influence the $\mathrm{O} / \mathrm{N}_{2}$ ratio in the thermosphere, and thus "may contribute to seasonal variations in the thermosphere, particularly the asymmetry between solstices that cannot be explained by other mechanisms."

\subsection{Comparing extremes of solar activity}

The second possible application of linking short-term storm effects to long-term morphology patterns deals with results comparing storm strength (Fig. 11) to those dealing with extremes of the solar cycle (Fig. 9). Should we anticipate that the ionospheric response to moderate $K_{p}$ storms (panel 11a) and very strong $K_{p}$ storms (panel 11c) will be similar to effects seen during solar minimum storms (Fig. 9a) versus solar minimum storms (Fig. 9b)? The solar cycle patterns show that SSMAX storms have a deeper negative phase, but a faster recovery than SSMIN storms. Interestingly, the severity analysis also showed that the strongest storms had a deeper negative phase and a faster recovery than the moderate storms. These results speak to the nature of recovery, to the time constant for relaxation of a perturbed thermosphere, but the message lacks clarity. The ionospheric-thermosphere system appears to recover more rapidly from a larger imposed stress than from a smaller one. The possibility of such a system-sensitivity function merits more study via analysis of data from other sources and solar cycles, as well as from global modeling efforts.

\subsection{Assessing geophysical equivalency}

In this attempt to test our understanding of ionospheric storm processes as truly global phenomena, we introduced the concept of geophysically-equivalent sites in each hemisphere and produced average storm patterns under a variety of conditions. Overall, the coherence of these patterns provided a robust confirmation that solar-terrestrial physics includes a "geo-effectiveness" component that is indeed the same at locations of comparable geographic and geomagnetic coordinates. The small departures from these trends pointed to refinements in our understanding, under the assumption that the sites chosen were "identical" within possible limits. Table 1 shows that Wallops Island, in fact, is at a lower latitude than Hobart by about 4 degrees in both coordinate systems. We have argued that pre-conditions are important (and therefore solar production) and showed in Fig. 12a that the F-layers during summers at each site do not point to any significant difference due to the $\sim 4$ degrees of latitude. We also argued that proximity to auroral input is important for such sites because high latitude sources of electrodynamics, winds and composition changes contribute to both positive and negative phases. The cleanest example of Hobart having a smaller positive phase but a deeper and longer-lived negative phase occurred in our analysis of storms during the declining phase of the solar cycle (Fig. 9d). Could this be due primarily to Hobart having a higher geomagnetic latitude than Wallops Island?

To examine this possibility, we have analyzed ionospheric storms for the same years of the declining solar cycle using data from the ionosonde at Christchurch, New Zealand, a station that has a geographic latitude of $46^{\circ} \mathrm{S}$ and a magnetic latitude of $50^{\circ} \mathrm{S}$ (and thus nearly identical to Wallop Island's in Table 1). The results appear in Fig. 13. Here we display the storm-time pattern from Christchurch data obtained from the same set of 84 storms used to obtain the patterns for Wallops Island and Hobart in Fig. 9d, also reproduced 


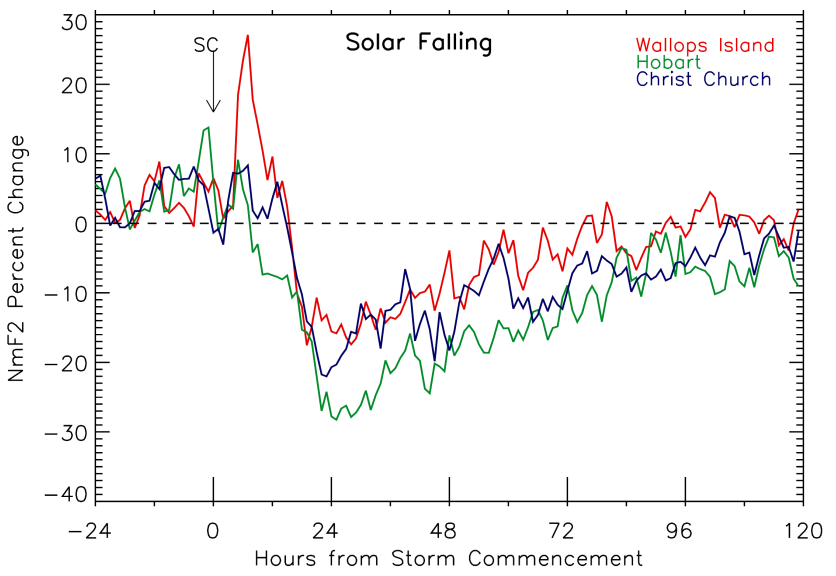

Fig. 13. Comparison of average patterns during solar declining phase at Wallops Island, Hobart and Christchurch stations. Their geomagnetic latitudes are $50.47^{\circ} \mathrm{N}, 54.05^{\circ} \mathrm{S}$ and $50.27^{\circ} \mathrm{S}$, respectively.

for comparisons in Fig. 13. Clearly, the positive phases at Christchurch and Hobart have similar magnitudes (with both much smaller than seen at Wallops Island), reinforcing the result that hemispheric difference occur for the positive phase. For the negative phases, the pattern at Christchurch is not as deep as seen at Hobart, suggestive that auroral heating processes have their expected latitude pattern, but the Christchurch pattern is still not in good agreement with Wallops Island most of the time, and particularly so when assessing the duration of the negative phase. Thus, we conclude that hemispheric differences (ceteris paribus) still occur and remain topics worthy of further study.

\section{Summary and conclusions}

We have conducted a new investigation of ionospheric storms at two sub-auroral ( $\sim$ midlatitude) sites that share similar geographic and geomagnetic latitudes, but in different hemispheres, conditions we call "geophysically-equivalent sites". Because of the significant tilt of the geomagnetic field axis with longitude, the results obtained can be related to seasonal, longitudinal and hemispheric differences. We find (as others before us) that the local time of the onset of a geomagnetic storm exerts a strong influence on the occurrence of positive and negative phases for each storm, and that the depth of the negative phase is linked to the severity of the geomagnetic storm. Differences also occur that relate to the phase of the solar cycle in which a storm occurs. When such factors are taken into account, we find that the average statistical patterns of storm-time effects are remarkably similar. Subtle differences remain, however, and they point to possible modulations of solar wind-magnetospheric-ionosphericthermospheric couplings during storms that depend fundamentally upon hemispheric conditions (as opposed to sea- sonal conditions). In addition to understanding these basic aspects of solar-terrestrial disturbances, such studies might point to an improved understanding of differences in the seasonal and hemispheric morphologies of the ambient F-layer ionosphere.

The results offered here are a first step in an ongoing investigation of coherence and consistency of storm effects during many solar cycles. While additional solar cycles are being addressed using archived observations, additional modeling studies, such as conducted by Burns et al. (2004) for solar cycle effects, are of crucial importance. This is especially true when they begin to explore results from hemispheric differences driven by auroral input and convection patterns that are different - not only because the seasons are different but perhaps as intrinsic hemispheric effects as well. Such an approach has been used in specific case studies of storm effects with the TIE-GCM driven by AMIE patterns (Emery et al., 1999), and thus more comprehensive sets of storms, or statistical results built from many model storm scenarios, is an approach worth considering.

Acknowledgements. This work was supported, in part, by the NASA Living With a Star program. We are grateful for discussions with Barbara Emery, Liying Gian, L. Lei and Alan Burns at NCAR. We acknowledge the archives of ionospheric and geomagnetic data that make this type of study possible, and urge that government support in host countries for the World Data Centers continue in these times of fiscal stress.

Topical Editor M. Pinnock thanks J. Lei and A. Burns for their help in evaluating this paper.

\section{References}

Balan, N. and Rao, P. B.: Dependence of ionospheric response on the local time of sudden commencement and the intensity of geomagnetic storms, J. Atmos. Terr. Phys., 52, 269-275, 1990.

Barth, C. A., Baker, D. N., and Mankoff, K. D.: Magnetospheric control of the energy input into the thermosphere, Geophys. Res. Lett., 29, 1629, doi:10.1029/2001GL014362, 2002.

Baumgardner, J., Wroten, J., Semeter, J., Kozyra, J., Buonsanto, M., Erickson, P., and Mendillo, M.: A very bright SAR arc: implications for extreme magnetosphere-ionosphere coupling, Ann. Geophys., 25, 2593-2608, 2008, http://www.ann-geophys.net/25/2593/2008/.

Burns, A. G., Killeen, T. L., Wang, W., and Roble, R. G.: The solar-cycle-dependent response to geomagnetic storms, J. Atmos. Solar-Terr. Phys., 66, 1-14, 2004.

Burns, A. G., Solomon, S. C., Wang, W., and Killeen, T. L.: The ionospheric and thermospehric response to CMEs: Challenges and successes, J. Atmos. Solar-Terr. Phys., 69, 77-85, 2007.

Duncan, R. A.: F-region seasonal and magnetic-storm behaviour, J. Atmos. Terr. Phys., 31, 59-70, 1969.

Emery, B. A., Lathuillere, C., Richards, P. G., Roble, R. G., Buonsanto, M. J., Knipp, D. J., Wilkinson, P., Sipler D. P., and Niciejewski, R.: Time dependent thermospheric neutral response to the 2-11 November 1993 storm period, J. Atmos. Solar Terr. Phys., 61, 329-350, 1999. 
Emery, B., Coumans, V., Evans, D., Germany, G., Greer, M., Holeman, E., Kadinsky-Cade, K., Rich, F., and Xu, W.: Seasonal, $\mathrm{Kp}$, solar wind and solar flux variations in long-term single-pass satellite estimates of electron and ion auroral hemispheric power, J. Geophys. Res., 113, A06311, doi:10.1029/2007JA012866, 2008.

Emery, B., Richardson, I., Evans, D., and Rich, F.: Solar wind structure sources and periodicities of auroral electron power over three solar cycles, J. Atmos. Solar-Terr. Phys., in press, 2009.

Essex, E. A., Mendillo, M., Schödel, J. P., Klobuchar, J. A., da Rosa, A. V., Yeh, K. C., Fritz, R. B., Hibberd, F. H., Kersley, L., Koster, J. R., Matsoukas, D. A., Nakata, Y., and Roelofs, T. H.: A global response of the total electron content of the ionosphere to the magnetic storms of 17 December and 18 June 1972, J. Atmos. Terr. Phys., 43, 293-306, 1981.

Foster, J., Buonsanto, M. J., Mendillo, M., Nottingham, D., Rich, F., and Denig, W.: Coordinated stable auroral red arc observations: Relationship to plasma convection, J. Geophys. Res., 99, 11429_ 11439, 1994.

Forster, J. C. and Rideout, W.: Midlatitude TEC enhancements during the October 2003 superstorm, Geophys. Res. Lett, 32, L12904, doi:10.1029/2004GL021719, 2005.

Fuller-Rowell, T. J., Codrescu, M. V., Rishbeth, H., Moffett, R. J., and Quegan, S.: On the seasonal response of the thermosphere and ionosphere to geomagnetic storms, J. Geophys. Res., 101, 2343-2353, 1996.

Hibberd, F. H. and Ross, W. J.: Variations in total electron content and other Ionospheric parameters associated with magnetic storms, J. Geophys. Res., 72, 5331-5337, 1967.

Gasda, S. and Richmond, A. D.: Longitudinal and interhemispheric variations or auroral ionospheric electrodynamics in a realistic geomagnetic field, J. Geophys. Res., 103, 4011-4021, 1998.

Lanzerotti, L. J., Cogger, L. L., and Mendillo, M.: Latitude dependence of ionosphere total electron content: Observations during sudden commencement storms, J. Geophys. Res., 80, 12871306, 1975.

Lei, J., Wang, W., Burns, A., Solomon, S., Richmond, A., Wiltberger, M., Goncharenko, L., Coster, A., and Reinisch, B.: Observations and simulations of the ionospheric and thermospheric response to the December 2006 geomagnetic storm: Initial phase, J. Geophys. Res., 113, A01314, doi:10.1029/2007JA012807, 2008.

Matsushita, S.: A study of the morphology of ionospheric storms, J. Geophys. Res., 64, 305-321, 1959.

Matuura, N.: Theoretical models of ionospheric storms, Space Sci. Rev., 13, 124-189, 1972.

Mendillo, M.: Ionospheric total electron content behavior during geomagnetic storms, Nature, 234, 23-24, 1971.

Mendillo, M.: A study of the relationship between geomagnetic storms and ionospheric disturbances at mid-latitudes, Planet. Space Sci., 21, 349-358, 1973.
Mendillo, M.: Storms in the ionosphere: Patterns and processes for total electron content, Rev. Geophys., 44, RG4001, doi:10.1029/2005RG000193, 2006.

Mendillo, M., Huang, C.-L., Pi, X.-Q., Rishbeth, H., and Meier, R.: The global asymmetry in ionospheric total content, J. Atmos. Solar-Terr. Phys., 67, 1377-1387, 2005.

Mendillo, M. and Klobuchar, J. A.: Total electron content: Synthesis of past storm Studies and needed future work, Radio Sci., 41, RS5S02, doi:1029/2005RS003394, 2006.

Mendillo, M., Papagiannis, M. D., and Klobuchar, J. A.: Average behavior of the midlatitude F-region parameters $\mathrm{N}_{T}, \mathrm{~N}_{\max }$ and $\tau$ during geomagnetic storms, J. Geophys. Res., 77, 4891-4895, 1972.

Mendillo, M., Klobuchar J. A., and Hajeb-Hosseinieh, H.: Ionospheric disturbances: Evidence for the contraction of the plasmasphere during severe geomagnetic storms, Planet. Space Sci., 22, 223-236, 1974.

Mendillo, M., He, X.-Q., and Rishbeth, H.: How the effects of winds and electric fields in F2-layer storms vary with latitude and longitude: A theoretical study, Planet. Space Sci., 40, 595-606, 1992.

Obayashi, T.: Morphology of storms in the ionosphere, Res. Geophys., 1, edited by: Odishaw, H., MIT Press, Cambridge, MA, 335-366, 1964.

Qian, L., Solomon, S. C., and Kane, T. J.: Seasonal variation of thermospheric density and composition, J. Geophys. Res., 114, A01312, doi:10.1029/2008JA013643, 2009.

Prölss, G. W.: Ionospheric F-Region Storms, in: Handbook of Atmospheric Electrodynamics, vol. 2, edited by: Volland, H., CRC Press, Boca Raton, FL USA, Ch. 8, pp. 195-248, 1995.

Ridley, A.: Effects of seasonal changes in the ionospheric conductances on magnetospheric field-aligned currents, Geophys. Res. Lett., 34, L05101, doi:10.1029/2006GL028444, 2007.

Rishbeth, H.: Ionospheric storms and the morphology of magnetic disturbances, Planet. Space Sci., 11, 31-43, 1963.

Rishbeth, H. and Garriott, O. K.: Introduction to Ionospheric Physics, Academic Press, International Geophys. Series \#14, New York, 1969.

Rishbeth, H. and Müller-Wodarg, I. C. F.: Why is there more ionosphere in January than in July? The annual asymmetry in the F2-layer, Ann. Geophys., 24, 3293-3311, 2006, http://www.ann-geophys.net/24/3293/2006/.

Schunk, R. W. and Nagy, A. F.: Ionospheres: Physics, Plasma Physics and Chemistry, Cambridge Univ. Press, Cambridge, UK, 2nd ed., 2009.

Stenbaek-Nielsen, H. C. and Otto, A.: Conjugate auroras and the interplanetary magnetic field, J. Geophys. Res., 102, 2223-2232, 1997.

Taylor, J. R.: An Introduction to Error Analysis, University Science Books, Sausalito, CA USA, 2nd ed., Ch. 4, pp. 102-103, 1997. 